\title{
Analysis of Regional Wage Difference in Labor Market Discrimination
} Ziming Zhou*, Yiming Bu, Xiang Gao

Nanjing University of Information Science \& Technology, Nanjing 210044, Jiangsu province, China. E-mail: 201833060048@nuist.edu.cn

\begin{abstract}
Based on geographical isolation, dual labor market and other factors, the development of China's different regional economy has obvious characteristics of differentiation, which can be embodied in the phenomenon of "different salaries for the same work" and "different workers with the same salary". In order to further analyze its influence, this paper analyzes the regional discrimination in the free labor market with the help of the multiple regression analysis model of regional wage and remuneration in economics, referring to the factors such as region, occupation, expenditure cost and labor market, and on the basis of studying the influence of labor market discrimination, wage difference and human resources on labor remuneration.
\end{abstract}

Keywords: Labor Market Discrimination; Regional; Wage Difference

\section{The research background}

\subsection{The influence mechanism of regional discrimination on wage difference}

Different geographical areas: The industrial characteristics of the eastern, central and western regions are different. Therefore, in the process of talent introduction, local industrial development needs and planning are emphasized, leading to obvious differences in the level of labor force gathered in the regions. According to the data, the overall wage difference rate in eastern China is $17.75 \%$, while that in central and western China is as high as $51.13 \%{ }^{[1]}$.

Same geographical area: In the same geographical area, according to the different economic development conditions of different regions, it can be mainly divided into urban areas and rural areas. In the process of labor market development, there is a significant dual structure of urban and rural development in all provinces and cities in China. Due to different development starting points, different resource allocation and different talent reserves, the economic development of each region presents an olive type.

\subsection{A review of the relationship between regional discrimination and wage dif- ferences}

Regional discrimination is prevalent in China's labor market now. The main reason for this phenomenon is geographical isolation, which leads to the difference of wage compensation. Wang Gewei (2004) found that in 90s, with the help of improved immigration network and perfect registered residence system, the number of rural migrants to city increased by $35 \%$ in the 10 years, and the income gap between urban and rural areas expanded by about $10 \%$ in China in the 10 years. Deng Quheng (2007) studied the CHIP of the Chinese Academy of Social Sciences in 2002, finding that $60 \%$ of the income gap between urban and rural residents is due to regional discrimination, which cannot be explained by the theory of labor human capital difference ${ }^{[2]}$. Han Yiqiao (2019) found that in the eastern urban labor market, the 
wage difference between urban and rural labor (67.15\%) is higher than that between professional posts $(32.85 \%)$. Wang Mingming (2019) found that wage differentials decomposition method Oaxaca-Blinder decomposes 50.87\% of wage differentials from registered residence discrimination registered residence discrimination.

\section{The development of Regional Wage remuneration in the free labor mar- ket}

\subsection{Income and expenditure of residents}

\subsubsection{Income and expenditure of urban and rural residents}

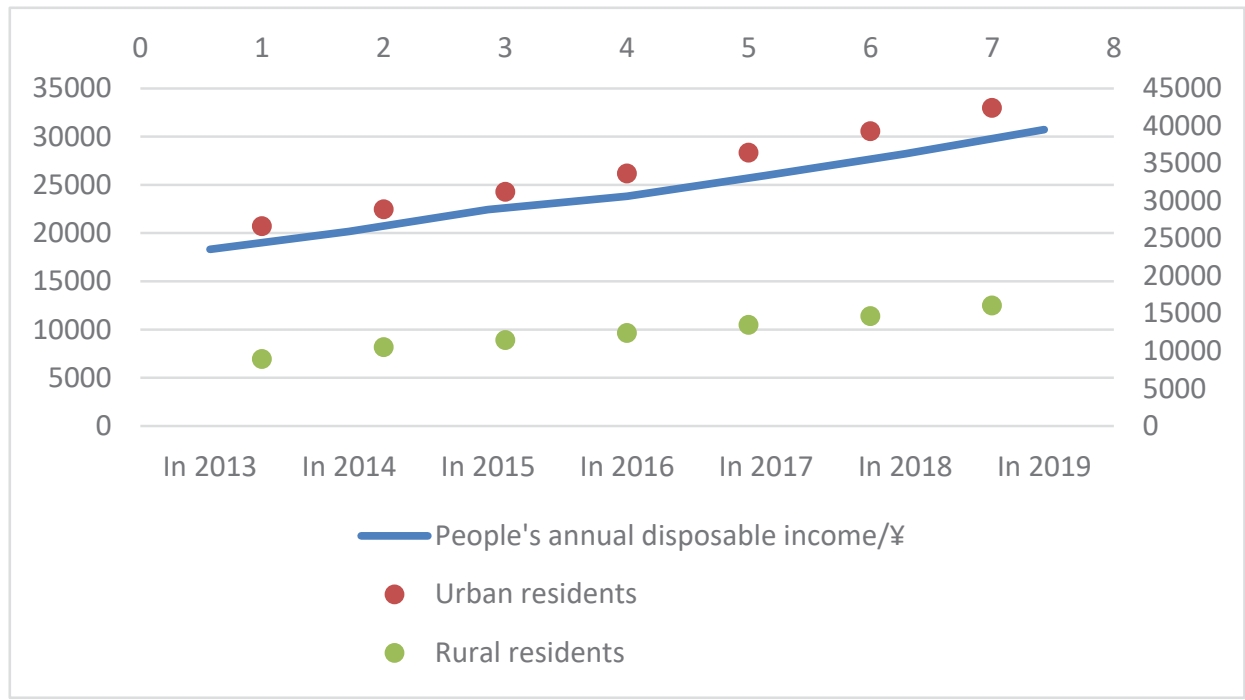

Figure 1. Comparison of per capita disposable income of urban and rural residents in 2013-2019.

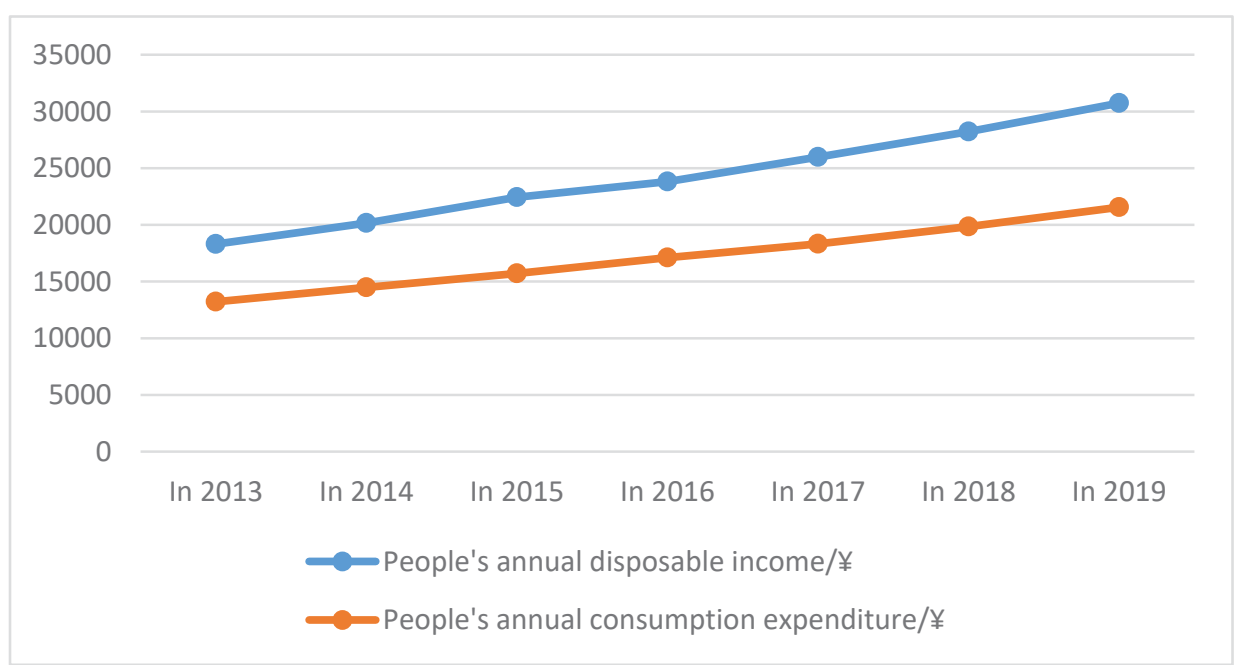

Figure 2. People's annual disposable income and people's consumption expenditure in 2013-2019.

Referring to the per capita disposable income and consumption expenditure of urban and rural residents from 2013 to 2019, the overall economic income and consumption of residents show a stable growth trend. However, the overall level of cities and towns is always higher than the national per capita economic income and consumption indicators under the same conditions, and the overall level of rural areas is always lower than the national per capita economic income and consumption indicators under the same conditions.

\subsubsection{The situation and income of eastern and mid-western residents in China}

When comparing the income gap between urban and rural residents in 19 years, after deducting the price factor, the growth rate of rural per capita disposable income was $6.2 \%$, which is higher than that of the national and urban per cap- 
ita disposable income growth rate of 5.8\% and 5.0\% under the same conditions.

\begin{tabular}{|c|c|c|c|c|c|c|}
\hline \multirow{2}{*}{ Indicators } & \multicolumn{2}{|c|}{ Entire province residents } & \multicolumn{2}{|c|}{ Urban residents } & \multicolumn{2}{|c|}{ Rural residents } \\
\hline & Absolute amount// & Year-on-year growth rate & Absolute amount/f & Year-on-year growth rate & Absolute amount/f & Year-on-year growth rate \\
\hline $\begin{array}{l}\text { people's annual } \\
\text { disposable } \\
\text { income }\end{array}$ & 49899 & 8.9 & 60182 & 8.3 & 29876 & 9.4 \\
\hline 1-Wage income & 28511 & 8.6 & 33663 & 8.1 & 18480 & 9.4 \\
\hline 2-0perating incom & 8498 & 9.6 & 9115 & 9.6 & 7296 & 9.3 \\
\hline 3-Asset income & 5708 & 8.8 & 8202 & 8.1 & 852 & 8.6 \\
\hline 4-Transfer income & 7182 & 8.8 & 9202 & 8.0 & 3248 & 10.4 \\
\hline $\begin{array}{l}\text { people's } \\
\text { consumption } \\
\text { expenditure }\end{array}$ & 32026 & 8.7 & 37508 & 8.4 & 21352 & 8.3 \\
\hline
\end{tabular}

Figure 3. Main indicators of per capita income and expenditure of Zhejiang Residents in 2019.

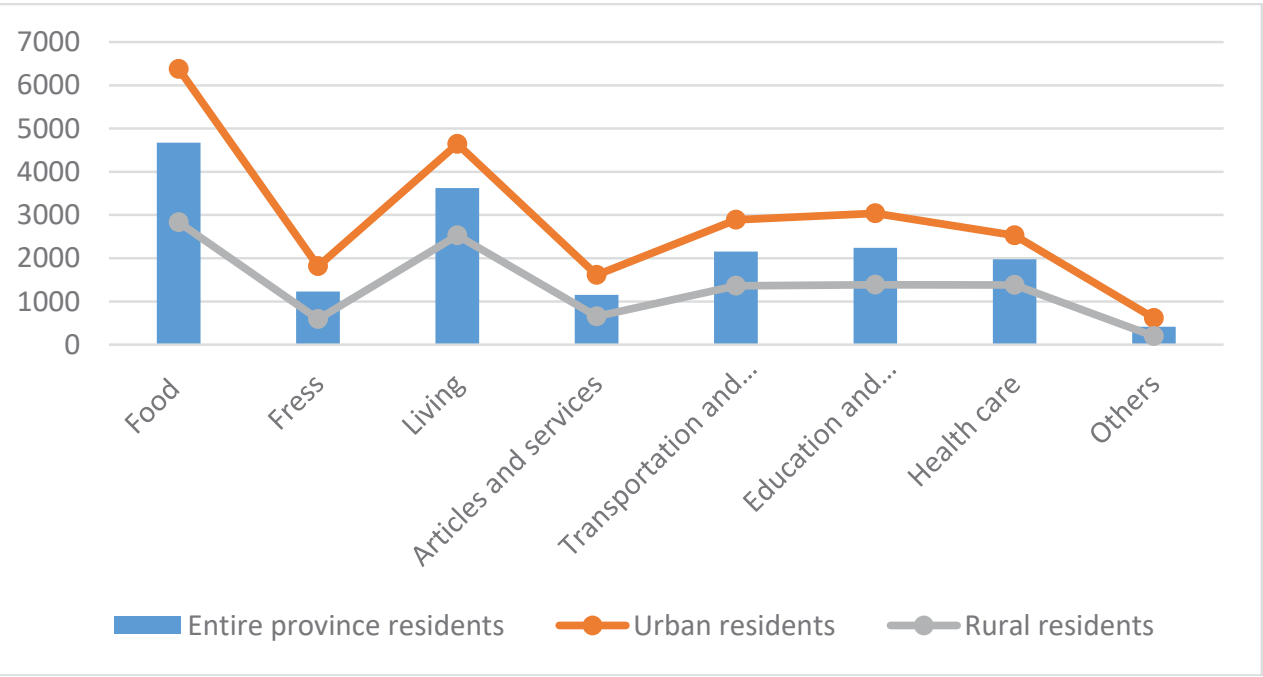

Figure 4. Per capita living consumption expenditure of Shaanxi residents in 2019.

\section{Research methods and data models}

\subsection{Data and variables}

\subsubsection{Data}

The data used in this paper are the survey data of the National Bureau of statistics of China and the statistical bureaus of various provinces and cities from 2013 to 2019.

\subsubsection{Variable selection}

Region: We divide regions according to different geographical regions, including the eastern, central and western regions; according to the different economic development conditions of the same region, including towns and villages.

Occupation: We mainly study the difference of wage income between different occupations and the wage levels of the same occupation in different regions, dividing them into the first industry, the second industry and the third industry.

Expenditure cost: We mainly analyze the level of enterprise and individual expenditure cost, and then study the correlation between it and income.

Dual labor market: The labor market is mainly divided into two major sectors: the main sector and the secondary sector.

\subsubsection{Empirical model}

In this paper, the correlation coefficient of the equation model is set by combining the factors of region, occupation, expenditure cost and dual labor market. 


$$
\mathrm{y}=\beta_{0}+\beta_{1} \times \text { region }+\beta_{2} \times \text { career }+\beta_{3} \times \text { cost }+\beta_{4} \times \text { market }_{1}+\beta_{5} \times \text { market }_{2}+\lambda
$$

In the above formula, $y$ is the wage remuneration of workers. The reference value can be annual income, monthly income or daily income. In practical application, this paper selects the per capita annual disposable income. Specifically, region stands for region, career for occupation, cost for expenditure, market 1 for major sectors of dual labor market, and market 2 for major sectors of dual labor market ${ }^{[3]}$.

\subsection{Statistical analysis of regional employment and regional wage remuneration}

\subsubsection{Analysis of regional factors}

The following is analysis of the per capita annual income gap between urban and rural labor force. Through the analysis of the data from 2013 to 2019, the income gap between urban and rural areas is obvious. The annual income gap per capita has expanded from 16,648 yuan in 2013 to 26,338 yuan in 2019, but the multiple differences have narrowed from 3.10 times in 2013 to 2.64 times in 2019. Moreover, with the passage of time, the per capita disposable income of the two groups increased steadily every year. At the same time, the annual per capita disposable income growth rate in rural areas has gradually exceeded that in urban areas under the same conditions.

Through the analysis of the data from 2013 to 2019, the income gap between the east, the middle and the west is very obvious. From the perspective of "Eastern vs. Central" and "Eastern vs. Western", the per capita annual income gap has expanded from 9,718 yuan and 12,320 yuan in 2013 to 16,024.9 yuan and 18,981.5 yuan in 2019; however, the multiple difference is reduced from 1.62 times and 1.94 times in 2013 to 1.61 times and 1.83 times in $2019^{[4]}$. Moreover, over time, the per capita disposable income in the three regions has achieved steady annual growth. At the same time, the annual growth rate of per capita disposable income in central China has gradually exceeded that in the eastern and western regions.

\subsubsection{Analysis of industrial factors}

In the analysis results of the correlation between different industries and annual disposable income from 2013 to 2019, it is found in Pearson correlation that the impact of the primary industry, the secondary industry and the tertiary industry on the per capita annual disposable income is $99.4 \%, 98.3 \%$ and $99.8 \%$, respectively, which has obvious explicit correlation.

Table 1. Correlation analysis of different industries on per capita disposable income

\begin{tabular}{|l|l|l|l|l|l|}
\hline \multicolumn{2}{|l|}{ Relevance } & $\begin{array}{l}\text { Annual disposable } \\
\text { income per person }\end{array}$ & $\begin{array}{l}\text { National GDP / } 100 \\
\text { million yuan }\end{array}$ & $\begin{array}{l}\text { Primary indus- } \\
\text { try / 100 million } \\
\text { yuan }\end{array}$ & $\begin{array}{l}\text { Secondary indus- } \\
\text { try / } 100 \text { million } \\
\text { yuan }\end{array}$ \\
\hline \multirow{2}{*}{$\begin{array}{l}\text { Annual disposa- } \\
\text { ble income per } \\
\text { person }\end{array}$} & Pearson correlation & 1 & $.997^{* *}$ & $.994^{* *}$ & $.983^{* *}$ \\
\cline { 2 - 7 } & SIG. (double tail) & & .000 & .000 & .000 \\
\cline { 2 - 7 } & Number of cases & 7 & 7 & 7 & 7 \\
\hline
\end{tabular}

\subsubsection{Cost factor analysis}

The average annual consumption expenditure of domestic people increased from 13,220.42 yuan in 2013 to $21,558.85$ yuan in 2019 , with a year-on-year increase of $63.1 \%$; at the same time, the annual disposable income per capita increased by $67.8 \%$.

Table 2. Correlation analysis of consumption expenditure and per capita disposable income

\begin{tabular}{|l|l|l|l|}
\hline \multicolumn{3}{|c|}{ Correlation $^{\text {a }}$} \\
\hline \multirow{2}{*}{ particular year } & Annual disposable income per person & Per capita annual consumption expenditure \\
\cline { 2 - 4 } & Pearson correlation & .998 & .998 \\
\hline & SIG. (double tail) & .000 & .000 \\
\hline a. Column $\mathrm{n}=7$
\end{tabular}


The development of economy and society drives the increase of per capita disposable income, and then promotes people's corresponding consumption expenditure. On the other hand, by observing the increase or decrease of per capita consumption expenditure, we can infer the amount of people's disposable income ${ }^{[5]}$.

\subsubsection{Analysis of labor market factors}

Through the analysis of the correlation between the annual disposable income of residents in different provinces and cities and the impact of the dual labor market from 2013 to 2019, it is found that the correlation between the two is greater than $60 \%$, showing an obvious dominant correlation. At the same time, this paper also makes a variance analysis table, variable exclusion table, and comprehensively analyzes and quantifies the data.

Table 3. Correlation between annual disposable income and the impact of dual labor market in different provinces and cities from 2013 to 2019

\begin{tabular}{|l|l|l|l|l|l|l|l|l|}
\hline \multicolumn{2}{|c|}{} & $\begin{array}{l}\text { Time: } \\
2013\end{array}$ & $\begin{array}{l}\text { Time: } \\
2014\end{array}$ & $\begin{array}{l}\text { Time: } \\
2015\end{array}$ & $\begin{array}{l}\text { Time: } \\
2016\end{array}$ & $\begin{array}{l}\text { Time: } \\
2017\end{array}$ & $\begin{array}{l}\text { Time: } \\
2018\end{array}$ & $\begin{array}{l}\text { Time: } \\
2019\end{array}$ \\
\hline $\begin{array}{l}\text { Pearson } \\
\text { correlation }\end{array}$ & $\begin{array}{l}\text { Dual degree of labor } \\
\text { market influence }\end{array}$ & .662 & .661 & .658 & .651 & .658 & .640 & .635 \\
\hline
\end{tabular}

Table 4. Annual disposable income and dual labor market influence variable exclusion of provinces and cities from 2013 to 2019

\begin{tabular}{|c|c|c|c|c|c|c|c|}
\hline \multicolumn{8}{|c|}{ Excluded variable a } \\
\hline \multirow[t]{2}{*}{ Model } & \multirow[t]{2}{*}{ Enter beta } & \multirow[t]{2}{*}{$\mathrm{t}$} & \multirow[t]{2}{*}{ Significance } & \multirow{2}{*}{$\begin{array}{l}\text { Partial cor- } \\
\text { relation }\end{array}$} & \multicolumn{3}{|c|}{ Collinear statistics } \\
\hline & & & & & Tolerance & Lively & $\begin{array}{l}\text { Minimum } \\
\text { tolerance }\end{array}$ \\
\hline Time: 2014 & $.301 \mathrm{~b}$ & .425 & .674 & .079 & .039 & 25.967 & .039 \\
\hline Time: 2015 & $-5.719 b$ & -1.123 & .271 & -.204 & .001 & 1399.456 & .001 \\
\hline Time: 2016 & $-6.291 b$ & -2.017 & .053 & -.351 & .002 & 573.214 & .002 \\
\hline Time: 2017 & $-.261 \mathrm{~b}$ & -.161 & .873 & -.030 & .007 & 136.328 & .007 \\
\hline Time: 2018 & $-3.554 b$ & -2.098 & .045 & -.363 & .006 & 170.807 & .006 \\
\hline Time: 2019 & $-2.756 b$ & -1.990 & .056 & -.347 & .009 & 112.725 & .009 \\
\hline Time: 2014 & $.203 \mathrm{c}$ & .302 & .765 & .057 & .038 & 26.100 & .005 \\
\hline Time: 2015 & $8.643 \mathrm{c}$ & .998 & .327 & .185 & .000 & 4463.312 & .000 \\
\hline Time: 2016 & $-.877 \mathrm{c}$ & -.083 & .934 & -.016 & .000 & 6385.974 & .000 \\
\hline Time: 2017 & $2.427 \mathrm{c}$ & 1.317 & .199 & .241 & .005 & 207.256 & .004 \\
\hline Time: 2019 & $6.961 \mathrm{c}$ & .625 & .537 & .117 & .000 & 7234.437 & $9.122 \mathrm{E}-5$ \\
\hline \multicolumn{8}{|c|}{ a. Dependent variable: dual labor market influence degree } \\
\hline \multicolumn{8}{|c|}{ b. Prediction variables in the model: (constant), time: 2013} \\
\hline \multicolumn{8}{|c|}{ c. Prediction variables in the model: (constant), time: 2013 , time: 2018} \\
\hline
\end{tabular}

\section{The influence and thinking of the Regional Wage Difference}

\subsection{Wage discrimination}

The most direct manifestation of regional discrimination is the differentiation of wage and price level. By comparing the wage salary treatment of different groups in different regions and referring to the statistical data in 2013-2019, taking the average annual disposable income of Zhejiang Province in eastern cities as 39,138.38 yuan as an example, 
the average annual disposable income of Hubei Province in the central city is 22,065.61 yuan, and that of Gansu Province in western city is $14,844.81$ yuan.

At present, the state has issued standards to guarantee the people's minimum living standards, but the gap between the rich and the poor is still prominent and obvious.

\subsection{Employment rate difference}

Different regions develop different industries and provide different jobs. The resource allocation among the east, the middle and the west, or between urban and rural areas are not consistent. And the industries developed according to their own resource advantages have their own advantages. In the analysis of employment data from 2013 to 2019 , the number of urban employment increased from 382.4 million in 2013 to 442.47 million in 2019, with a year-on-year increase of $15.7 \%$; the number of rural employment decreased from 387.37 million in 2013 to 332.24 million in 2019 , a year-on-year decrease of $14.2 \%{ }^{[6]}$.

This requires the region to further adjust the industrial structure, reasonably optimize the measures of talent introduction, and adhere to the diversification and multi form recruitment of human resources while developing the advantageous industries.

\subsection{Occupational segregation}

Due to geographical factors, occupational segregation forces individuals in the same position to receive differential wage treatment in different regions, which can be summarized as the phenomenon of "different salaries for the same work". At the same time, under the same salary level, the job requirements in different regions are also different, which can be summarized as the phenomenon of "different workers with the same salary". In the analysis of the industrial residential income data in 2019, taking two different industries of the city as the research object, it is found that the average wage of the employees represented by the state-owned enterprises is 98,899 yuan, while that of the real estate enterprises represented by the private enterprises is 51,393 yuan.

In order to balance the wage differences caused by occupational segregation, it is necessary to further strengthen the links and coordination between different regions and the same industry, and reduce the differential results caused by "different salaries for the same worker".

\subsection{Population mobility}

Population mobility can be divided into low-end market labor outflow and talent introduction. In the developed eastern and urban areas, the income return rate of low-end labor force is higher than that of high-end market, and experience and work tolerance are the important reasons for the high return rate. In economically backward areas, the education level of the talents in the economically backward areas is recognized by the market.

According to the data of the National Bureau of statistics, China's annual population flow in 2015 was 247 million, a decrease of 6 million compared with 2014; the annual population flow in 2016 was 245 million, decreased by 1.71 million compared with 2015; in 2017, the annual population flow was 244 million, continuing to shrink by about 820000. From 2018 to 2019, the annual population flow also continued to show a downward trend. At the same time, in the comparison of population mobility data of major cities in China in 2019, with the permanent floating population as the reference system, Shanghai ranks first with 9.7269 million people, followed by Guangzhou with 9.6733 million people and Shenzhen with 8.1811 million people.

In the promotion of the market economy, regional population mobility has also brought some benefits. This has realized the free flow and sharing of human resources between different regions. It not only provides various professional talents for the development of various regions, but also provides sufficient labor supply, which also brings about the improvement of employment rate.

\subsection{Salary structure adjustment}

At present, due to the different levels of economic development between the East, the middle and the west, the 
minimum wage standards proposed by different regions are also different. Taking Zhejiang Province as an example, the four levels of minimum wage standards in Zhejiang Province in 2019 are 2010 yuan per month, 1800 yuan per month, 1660 yuan per month and 1500 yuan per month; in Central China, Henan Province as an example, the three levels of minimum wage standards in Henan Province in 2019 are 1900 yuan per month, 1700 yuan per month and 1500 yuan per month; in western Gansu Province, for example, the four levels of minimum wage standards in Gansu Province in 2019 are 1620 yuan per month, 1570 yuan per month, 1520 yuan per month and 1470 yuan per month ${ }^{[7]}$. It is found that the gap among the east, the middle and the west is very intuitive, combined with urban and rural, occupation and other factors, the wage gap caused by regional factors is more prominent.

On the premise of fully considering the change trend of salary structure, it is necessary to consider the economic development level of different regions, balance the proportion of high paid personnel, adjust the salary proportion of bottom workers, and adjust the overall wage standard and wage return rate.

\section{Conclusion}

With the rapid development of socialist economy, different regional groups in China have been treated differently in the labor market ${ }^{[8]}$. In the eastern, central and western regions of different geographical regions, as well as urban and rural areas with different levels of economic development, this performance is extremely obvious. In the process of the study, we combined the factors of occupation, gender, expenditure cost and labor market to further expand the wage gap of regional discrimination. Finally, it is found that the income gap of more than $50.8 \%$ among the eastern, central and western regions and between urban and rural areas, which is caused by regional discrimination. This also urges the next development of the market economy, not only to maintain stable and healthy growth, but also to coordinate and promote the adjustment of salary structure in different regions and improve the level of wage security.

\section{References}

1. Han Y. Regional differentiation of employment opportunities and wage differences in urban labor market. Western Academic Journal 2019; (21): 98 - 100.

2. Zhu Hi, Zheng H. Regional wage gap in China's urban labor market: a case study of Shanghai. Finance and Trade Economy 2013; (07): 115 - 125.

3. Mo R. Four new trends will appear in China's labor market development. CPPCC news; 2019.

4. Niu Y. Comparative analysis of labor remuneration difference between urban and rural residents in Zhejiang. Statistical Science and Practice 2014; (05): 27 - 29.

5. Wang M. Study on wage differentials based on registered residence discrimination. Dongbei University of Finance and Economics 2019.

6. Wang G. The impact of regional income gap on rural labor migration -- Based on the data of the fifth national census. Economics (quarterly) 2004; (S1): 77 - 98.

7. Nameless. The relationship between intellectual property rights and China's economic development today (in Chinese). 2020. p. 137.

8. Yu M. International standards and Chinese practice of anti-social origin employment and occupational discrimination. Hebei academic journal 2015; 35 (04): 132 - 136. 